\title{
Article
}

\section{Mental Health and Wellbeing Benefits from a Prisons Horticultural Programme}

Farrier, Alan, Baybutt, Michelle and Dooris, Mark T

Available at http://clok.uclan.ac.uk/23792/

Farrier, Alan ORCID: 0000-0003-4989-2209, Baybutt, Michelle ORCID: 00000002-3201-7021 and Dooris, Mark T ORCID: 0000-0002-5986-1660 (2019) Mental Health and Wellbeing Benefits from a Prisons Horticultural Programme. International Journal of Prisoner Health, 15 (1). pp. 91-104. ISSN 1744-9200

It is advisable to refer to the publisher's version if you intend to cite from the work. http://dx.doi.org/10.1108/JJPH-11-2017-0055

For more information about UCLan's research in this area go to

http://www.uclan.ac.uk/researchgroups/ and search for <name of research Group>.

For information about Research generally at UCLan please go to http://www.uclan.ac.uk/research/

All outputs in CLoK are protected by Intellectual Property Rights law, including Copyright law. Copyright, IPR and Moral Rights for the works on this site are retained by the individual authors and/or other copyright owners. Terms and conditions for use of this material are defined in the policies page. 
International Journal of Prisoner Health

Mental Health and Wellbeing Benefits from a Prisons Horticultural Programme

Author Details:

Dr. Alan Farrier

Healthy and Sustainable Settings Unit

Faculty of Health and Wellbeing

University of Central Lancashire

Preston

UK

Dr. Michelle Baybutt

Healthy and Sustainable Settings Unit

Faculty of Health and Wellbeing

University of Central Lancashire

Preston

UK

\section{Prof. Mark Dooris}

Healthy and Sustainable Settings Unit

Faculty of Health and Wellbeing

University of Central Lancashire

Preston

UK

Corresponding author: Alan Farrier

afarrier@uclan.ac.uk 


\begin{abstract}
Purpose

In the context of current prison safety and reform this paper discusses findings of an impact evaluation of a horticultural programme delivered in 12 prisons in North West England.
\end{abstract}

\title{
Design
}

The programme was evaluated using quantitative and qualitative methods, including Green Gym ( $)$ questionnaires, the Warwick Edinburgh Mental Wellbeing Scale (WEMWBS) and Biographic-Narrative Interpretive Method (BNIM) interviews.

\section{Findings}

Against a backdrop of high rates of suicide, self-harm and poor mental health, the horticultural programme studied proved beneficial to prisoner participants, the most marked effect was on mental health and wellbeing. In addition to data related to the original mental health outcome indicators, the study revealed multiple layers of 'added value' related to mental health arising from horticultural work in a prison setting.

\section{Research limitations}

The main research limitations were the limited completion of follow-on questionnaires due to prisoners being released and the inability to conduct longitudinal data collection postrelease. There was also concern about response bias and lack of resource to compare with the experience of prisoners not participating in the programme.

\section{Social implications}

Positive impacts on prisoners' mental health and wellbeing included increased confidence, social interactions with staff and other prisoners, and gaining skills and qualifications and work experience, increasing potential for post-release employment.

\section{Originality}

Benefits of horticulture work on health are well established. However, to date, there is little research concerning the effects this work may have on mental wellbeing of prisoners both within prisons and more so upon their release back into the community.

\section{Keywords}

Mental health, Prisoners, Horticulture, Rehabilitation, Qualitative research, Health promotion prison

\section{Background}

\section{Prisoners and mental wellbeing}

In England and Wales, increasing numbers of people are serving time in prison on custodial sentences (Public Health England, 2016). The 2016 prison population of England and Wales exceeded 85,000 (Allen and Watson, 2017), nearly double that two decades previously (Ministry of Justice, 2013a). Although $95.4 \%$ of this population is male (Ministry of Justice, 2014), the number of women in prison has more than doubled over the same period (Prison Reform Trust, 2017). 
Data consistently shows that prisoners have high levels of poor physical and mental health alongside poor levels of literacy, numeracy and educational achievement - and that these factors are strongly associated with offending behaviour (Social Exclusion Unit, 2002; HM Government, 2005). For example, $72 \%$ of male and $70 \%$ of female prisoners are affected by two or more mental health disorders (Prison Reform Trust, 2015). Suicide rates are significantly higher in custody than amongst the general population: $16 \%$ of the prison population have symptoms indicative of psychosis and $25 \%$ identify as suffering from anxiety and depression; and $46 \%$ of women and $21 \%$ of men have attempted suicide (Prison Reform Trust, 2016a). The Bradley Report (2009) showed more than $90 \%$ of young offenders had a common mental health problem noting that figures seem equally high for adult prisoners.

\section{Mental health and wellbeing opportunities in prison}

Mental ill-health in prisons is one of the most prevalent and challenging contemporary issues and is closely associated with high rates of suicide and self-harm in custody, serving to emphasise the importance of adequate support and tailored interventions (Prisons and Probation Ombudsman Independent Investigations, 2016). The prison environment can be particularly tough for those with mental health problems (The Bradley Report, 2009). Therefore, prison governors are encouraged to invest in a prison environment beneficial to mental wellbeing (Howard League for Penal Reform and Centre for Mental Health, 2016) enabling prisons to be a place of rehabilitative support (Prisons and Probation Ombudsman Independent Investigations, 2016). It is argued that all prisoners should be out of their cells during the working day, taking part in healthy, constructive and meaningful activities - as prisoners' risk of suicide is likely to increase significantly if they are isolated in their cell for hours on end with little to keep their mind occupied (Howard League for Penal Reform and Centre for Mental Health, 2016).

A Department of Health study (2004) argued "prison populations reveal strong evidence of health inequalities and social exclusion. This is a valuable opportunity to identify and tackle the broad health needs of a vulnerable and socially excluded population" (:129). Whilst it seems evident that prisons offer potential to improve the mental health and wellbeing of some of the most disadvantaged individuals in society (Baybutt et al., 2014), health and wellbeing interventions in prison are often focused on physical as opposed to mental dimensions (Woodall et al., 2014a), with a focus on the prevention of the spread of diseases (The Hepatitis C Trust, 2013). This reflects a reductionist rather than holistic approach (Warwick-Booth et al., 2012) and it has been suggested that health promotion concepts such as empowerment are incongruent with prison cultures that emphasise deterrence, punishment and reform (Woodall et al., 2014b).

Prisons need to become safer, healthier places if they are to halt the rise in prison suicides (Howard League for Penal Reform and Centre for Mental Health, 2016). The concept of a health promoting prison is not new - first set out by WHO in 1995 and adopted by H.M. Inspectorate of Prisons as part of their inspection criteria. While recognising the particular challenges involved in promoting health within the prison context, the strategy, Health Promoting Prisons: a shared approach (Department of Health, 2002), set out an aspiration of prisons as healthy settings with the potential for health improvement, rehabilitation and reform and enhancing the life chances of all who live and work there (Woodall, 2012). Therefore, a Health Promoting Prison is not just a prison with a health care department: it is a place where the whole regime is geared towards promoting the physical, mental and social 
health and wellbeing of prisoners and staff and should as far as possible, replicate the environment and services of the community while in a secure setting (Howard League for Penal Reform and Centre for Mental Health, 2016).

\section{Greener on the Outside for Prisons: Nature, Health and the Prison Setting}

Established in 2008, Greener on the Outside of Prisons (GOOP) is a programme of therapeutic horticulture and conservation work, currently operating in all 12 North West England public sector prisons. Now internally funded by participating prisons, GOOP was until 2015 part of the regional Target: Wellbeing portfolio, funded by Big Lottery. Informed by research demonstrating wide-ranging therapeutic benefits of contact with nature (Annerstedt and Wahrborg, 2011; Barton et al., 2016), it provides a coherent, holistic and joined-up approach to improving the health, wellbeing and life chances of prisoners and other key prison stakeholders. It delivers a range of integrated strategic environmental initiatives focused on improving wellbeing and quality of life, reducing health inequalities while impacting on resettlement and the drive to reduce re-offending. It has built capacity, adding value to existing provision and developing new capacity where it did not exist. Reflecting guidance from the National Offender Management Service (NOMS, 2015), the 'whole system' approach adopted to deliver the programme acknowledges that prisoners' health cannot be addressed in isolation from the health of the general population, since there is a constant interchange between prison and the broader community.

GOOP provides opportunities for prisoners to participate in horticultural and environmentallyfocused programmes that are locally determined and needs-led. Improving health through engagement with nature, GOOP has explored innovative ways to improve mental wellbeing, increase physical activity, and develop understanding of environmental issues and food growing, while enhancing prisoners' skills and employability. Reflecting the needs of different types of prison and categories of prisoner, there have been two main types of activity: inprison' therapeutic horticulture and community-based environmental 'outworking'. For the first, GOOP has designed creative new prison gardens in addition to developing and maintaining outdoor spaces in prisons; grown food, flowers and plants; and facilitated partnership delivery of NVQ accredited Levels 1 and 2 horticulture training courses. For the second, GOOP has organised contributions to landscaping and conservation in local communities by prisoners released on temporary licence (ROTL), and prisoners have, under supervision, presented their horticultural work at public events. In the prison environment, in which confinement and limited opportunities to be outdoors are often major experiences in prisoner life, GOOP has become a desirable programme for prisoners to become enrolled in. In total, over 4,500 prisoners in the North West participated in the GOOP programme between 2008 and 2015.

\section{Study Design and Methods}

From 2013-15, the Healthy and Sustainable Settings Unit at the University of Central Lancashire (UCLan) conducted an impact evaluation of the GOOP programme. Ethical approval was obtained from the National Offender Management Service (NOMS) and aUCLAn ethics committee. Key issues included secure storage of confidential data using passwordprotected and/or encrypted folders and informed consent to using data from monitoring 
forms and quotations from interviews. Prisoners' names were anonymised and each assigned a numbered code.

Building on an earlier process evaluation (Baybutt, et al., 2012), this mixed-method study aimed to determine GOOP's effect on the health and wellbeing of prisoners and explore how it affected their lives on a broader scale. Furthermore, the evaluation sought not only to inform future programme development for new sites, but also to improve GOOP by understanding "what works and why" in existing sites (Springett, 2001). A total of 897 prisoners participated in the programme during the timeframe of the evaluation (2013-2015). Data were gathered from eight prisons. Every prisoner who participated in GOOP during this time period was asked to participate in the evaluation, but this was on a voluntary basis and not a requirement of participation in the programme. Therefore the demographic of the participant group was broad and covered an age range of 18-65, both male and female prisons (seven male and one female), and with prisoners in category $B C$ and $D$ prisons, with sentences ranging from several weeks to life.

Whilst the programme and evaluation covered three health outcome areas (mental wellbeing, physical activity and healthier eating) stipulated by the funder, this paper presents and discusses data on the former. The mental wellbeing outcome indicators for the wider Target: Wellbeing portfolio focused on increased self-efficacy, an enhanced sense of community belonging and increased life skills ${ }^{1}$. Research tools were tailored for custodial use, as standard Target: Wellbeing evaluation questionnaires had been devised for community-based projects, rendering many of the questions insensitive and inappropriate for use in the prison setting (Giles, et al., 2010). It was therefore agreed that the GOOP evaluation would use two questionnaires: one adapted from TCV's Green Gym @ evaluation forms ${ }^{2}-$ administered at the start of prisoners' participation in GOOP to gather baseline data and again after approximately 12 weeks' participation; and the Warwick Edinburgh Mental Well-being scale (WEMWBS) ${ }^{3}$.Both evaluation methods attempt to ascertain differences in self-perception about wellbeing (physical and mental) through measurement scales in which the participants choose a score for themselves on particular issues. Comparison of the baseline and continuation forms show if the participant considers that they have had a positive improvement in each particular area. This particular aspect of the study design, to repeat the questionnaires to gather monitoring information, was therefore a requirement of the funders. These survey tools were tested in the 'pilot' GOOP site and approved by the funders. Data presented in this paper is a subset of the total data collected, focusing on the mental health

\footnotetext{
${ }^{1}$ These definitions taken from the Big Lottery outcome indicator monitoring forms used to evaluation the programme.
}
${ }^{2}$ The adapted Green Gym questionnaires contained 16 questions in the initial form and 31 in the continuation form.

${ }^{3}$ WEMWBS is a "14 positively worded item scale with five response categories" (NHS Health Scotland,

2006) for assessing a population's mental wellbeing. 
outcomes. A key aspect of the research design was appointing prison leads at each site responsible for the distribution and collection of all quantitative evaluation documentation. Due to prison security regulations, this was done using paper hard copies of all documents. Participants were assigned a code number used in place of their actual name to ensure confidentiality. GOOP supervisors at each prison site read through the documents with prisoners if there were any with literacy issues. Both initial and continuation forms are based on multiple choice questions and were completed within 15 minutes each.

Appreciating the benefits of triangulating data by gathering "information from different sources, using different methods which work together as an efficient design" (Almalki, 2016:292), the research team additionally conducted qualitative research by undertaking narrative interviews with a purposive sample $(n=12)$ of participants across four prisons (including one each of categories B, C, $\mathrm{D}^{4}$ and one women's prison). The lead researcher made several visits to each prison site prior to the interviews taking place, to familiarise themselves with the sites and to build rapport with potential interviewees, prior to approaching selected participants on the programme to ask if they would like to take part in an interview in which they could tell the story of their involvement in the programme. Information sheets were supplied and the format of the interviews was also given verbally. Consent forms were signed prior to each interview taking place.

The rich in-depth data generated through these interviews forms the major focus of this paper. Interviews were transcribed verbatim and analysed using the Biographic-Narrative Interpretive Method (BNIM). BNIM interviews (Wengraf, 2001) are framed by an open question, in this case concerning the impact of involvement with GOOP on the life-course. Questioning respects the system of relevance of the interviewee as it allows the individual to tell their story in the order they wish and focusing on what they feel is important, free from interruption or steering from the interviewer. As this interview is steered by the interviewee, the length of the interviews for this study varied between 25-50 minutes, in a place of the participant's choosing (this varied from inside a polytunnel to an outdoor classroom). It was made clear to the participants that the researchers were from a University independent of the prisons, funded by the same organisation as GOOP, and that we were evaluating the programme.

Interpretation is undertaken by a panel working its way hermeneutically and future blind through the transcript. The virtue of this is that it can focus as much on performance and gestalt and as on the substance of the interview (Farrier et al., 2017). This is invaluable for discerning the unstated motivations, affects and states of mind associated with personal wellbeing. This analysis was then developed into individual case studies to develop a detailed understanding of prisoners' experiences of participation and of the 'added value' outputs of the programme. These additional outputs, which all included a key focus on mental health and wellbeing, were then incorporated into the final Target: Wellbeing Portfolio Impact Report (Groundwork, 2015).

${ }^{4}$ In UK prisons, the security level in men's prisons runs from A (most secure) to D (least secure resettlement prison). The women's prison was the only one in the region therefore the same security levels do not apply. 


\section{Findings}

Findings are presented under 10 thematic headings, with illustrative participants' quotes used throughout:

- People feeling more confident to manage their everyday lives

- People experiencing increased opportunities for social interaction

- Participants reporting the new skills or knowledge gained

- Emotional development and behavioural change

- Impact of exposure to green space

- Improved relationships with staff

- Reconfiguration of traditional prisoner status

- Reconnection with local community

- Progression towards employment

- Improved personal and interpersonal wellbeing

Of these, the first three are mental health indicators proposed by the funders - supported by both quantitative and qualitative data (Table 1 summarises quantitative data); the next seven focus on additional elements relating to mental health and wellbeing, identified exclusively from case studies developed from qualitative data.

Improvements in these outcome areas were determined by progression up scales between the initial and continuation forms in either Green Gym (C) or WEMWBS forms: For the Green Gym (C questionnaires, statements have four choices on a scale: Strongly Disagree, Disagree, Agree or Strongly Agree. If participants' response to the statement moved up the scale from the initial questionnaire and they chose either Agree or Strongly Agree in the continuation questionnaire, they were counted as having an 'improvement' in that outcome indicator area. WEMWBS statements have five choices on a scale: None of the time, Rarely, Some of the time, Often and All of the time. Participants progressing to either Some of the time, Often or All of the time for relevant statements were counted as having an improvement in that outcome indicator area. When both sets of data were present, they were both required to show positive improvements as described above. However, in many cases, this data was only obtainable from either a Green Gym (C) questionnaire or WEMWBS form, due to incomplete data. The data were combined in Table 1. Where outcome indicators were determined by more than one question or statement, only participants who showed improvement in all relevant statements where data was available were counted as having shown improvement. 


\begin{tabular}{|c|c|c|c|c|c|}
\hline 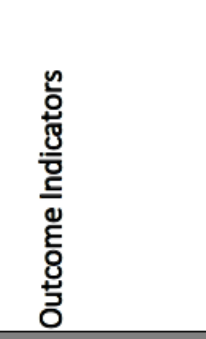 & 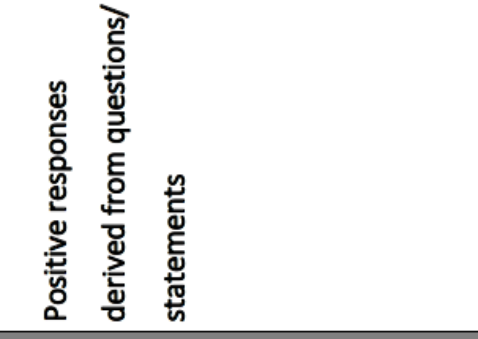 & 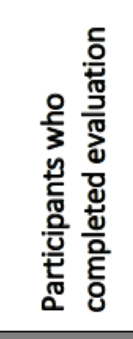 & 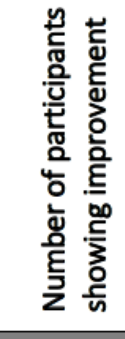 & 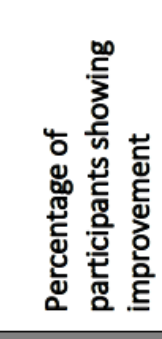 & 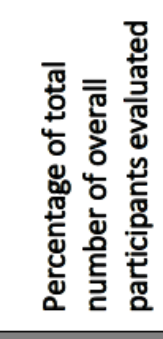 \\
\hline & \multicolumn{5}{|c|}{ ORIGINAL MENTAL HEALTH OUTCOME INDICATORS } \\
\hline $\begin{array}{l}\text { People } \\
\text { feeling more } \\
\text { confident to } \\
\text { manage their } \\
\text { everyday } \\
\text { lives }\end{array}$ & $\begin{array}{l}\text { Green Gym: I am confident in } \\
\text { passing on basic skills to others; I } \\
\text { feel more positive about myself } \\
\text { as a result of my involvement } \\
\text { with the group; Being involved in } \\
\text { the group makes me feel better } \\
\text { about myself } \\
\text { WEMWBS: I've been feeling } \\
\text { confident; I've been dealing with } \\
\text { problems well }\end{array}$ & 136 & 120 & $88.2 \%$ & $15.2 \%$ \\
\hline $\begin{array}{l}\text { People } \\
\text { experiencing } \\
\text { increased } \\
\text { opportunities } \\
\text { for social } \\
\text { interaction }\end{array}$ & $\begin{array}{l}\text { Green Gym: I have made new } \\
\text { friends as a result of working with } \\
\text { the group } \\
\text { WEMWBS: I've been feeling close } \\
\text { to other people }\end{array}$ & 135 & 128 & $94.8 \%$ & $15.1 \%$ \\
\hline $\begin{array}{l}\text { Participants } \\
\text { and/or } \\
\text { volunteers } \\
\text { reporting the } \\
\text { new skills or } \\
\text { knowledge } \\
\text { gained }\end{array}$ & $\begin{array}{l}\text { Green Gym: I have learnt new } \\
\text { skills through my involvement } \\
\text { with the group } \\
\text { WEMWBS: I've been interested in } \\
\text { new things }\end{array}$ & 137 & 118 & $86.1 \%$ & $15.3 \%$ \\
\hline
\end{tabular}

Table 1: Original mental health outcome indicators compiled from Green Gym and WEMWBS questionnaires $(\mathrm{n}=\mathbf{8 9 7})$

People feeling more confident to manage their everyday lives

In total $88.2 \%$ of participants showed a positive response in either. The case studies demonstrated the range of ways in which prisoners felt that their confidence levels and selfefficacy had been boosted by participating. Present in the stories of individual participants were ways in which GOOP helped them with their own mental health and wellbeing:

"I have suffered with mental health problems for over 25 years but working in the [horticulture] project has helped me to feel more confident". (Male prisoner)

"Being involved in the group has helped me with my social anxieties and helped me gain self-belief again". (Female prisoner)

One participant, with no horticultural experience and a history of prolific self-harm, described how the early days of participation in the programme saw a rapid transformation in her confidence: 
"I couldn't communicate, I didn't really talk...I've got quite severe mental health issues of post-traumatic stress and depression and anxiety...I was put on the horticulture course and I just loved it...I think they found that sort of within a couple of weeks I was talking a lot more. Yes, I did have bad days, where I was still self-harming... But I could communicate a lot better, my mental health was improving and I just really threw myself into doing my [NVQ] Level 1 in Horticulture". (Female prisoner)

Whilst involvement in the programme was not seen as a panacea for mental health issues such as self-harm, participants 'self-diagnosed' improvements in their mental health as a result of participation.

\section{People experiencing increased opportunities for social interaction}

Higher levels of social interaction were determined by an extremely positive response of $94.8 \%$. These results point to the social aspect of GOOP activities (interaction with the other participants in the programme) and the collaborative nature of the horticultural work benefits elaborated on in the narrative interviews:

"...I'll go with a colleague, you know, and we just work together...you work and you chat. We're social animals." (Male prisoner)

The group-working context was initially off-putting for some prisoners (for example, those with social anxiety). However, although group size ranged from 12 to 50 across 12 prisons, all were described favourably, with respondents highlighting how they comprised of like-minded individuals who help generate a good atmosphere. This resulted in some who were previously socially isolated in the prison setting having greater interaction with fellow prisoners:

"I love working [on the project] because I have learned to associate with people more." (Female prisoner)

Alongside increased levels of social interaction, participants highlighted the camaraderie engendered through involvement in GOOP, resulting in an increased sense of belonging enabling them to open up and express themselves more.

Participants reporting the new skills or knowledge gained

Acquisition of new life skills or knowledge received a positive response rate of $86.1 \%$. 'Learning' is a somewhat elastic term when it comes to GOOP, ranging from informal (participants exchanging tips and advice on growing produce) to accredited qualifications (some prisons offered City and Guilds courses, whilst others offered NVQ Levels 1 and 2 in horticulture, with ongoing discussions with college partners concerning the introduction of Level 3). However, its importance was made clear in qualitative interviews:

"I've learnt quite a lot during the time here, stuff that I wouldn't have picked up on the outside...I've learnt such a lot about growing stuff." (Male prisoner)

In one prison, with no formal courses running, there was still plenty of informal learning concerning gardening techniques and knowledge:

"[We have to] constantly keep on top of things in here with the plants all the time. Digging out the weeds, the last of them, taking out the plants, which are dying off, putting in some of the winter plants. There's a lot of labouring involved in here, in this jail...So it's been a learning curve." (Male prisoner) 
Horticulture is an educative experience, whether the learning is formal or informal, and this appears to be an important and distinct aspect of the GOOP experience. For the most dedicated participants, there was the reward of being engaged in garden design - being given increased responsibility through active involvement in creative decision-making.

Emotional development and behavioural change

Prisoners reflected on how participating in GOOP enabled them to address and deal more effectively with emotional issues and even change some entrenched and harmful personal patterns of behaviour:

"I'm encouraged to work on issues, not just to do with the work, but also personally, emotionally." (Female prisoner)

"I used to be a prolific self-harmer. And in the last eight years, no about nine years, I don't self-harm no more." (Female prisoner)

Participants also observed wider behavioural changes, which they understood to reflect increasing maturity:

"I've grown up in a lot of ways since being with the group as a whole." (Female prisoner)

Moreover, it is clear that prisoners have valued and forged connections to nature, and that this experience has helped them to cope with or resolve challenges:

"...it has been the making of me. I absolutely love it. Because it's like, when you put a seed in the soil, right, and then you watch it, and it's like, you're growing with that seed." (Female prisoner)

"... being out[side] actually helps tremendously, or shall I say... allows you to deal with your problems a lot better." (Male prisoner)

\section{Impact of exposure to green space}

The availability and size of outdoor space for horticulture varies between prisons. One participant described his current prison in which he is involved in the GOOP programme much more favourably to the one he was transferred from:

"In my previous prison] there was very limited garden jobs and you're in closed conditions...you go to a yard, just a yard for an hour a day. [After transferring to current prison] it felt good being able to walk out and about because after being banged up for so long, it's like the complete opposite." (Male prisoner)

Reflecting the findings above regarding connecting with nature, exposure to green space within the confines of harsh and claustrophobic prison environments often lacking in stimulation - was crucial, especially for prisoners who are not eligible for ROTL. One prisoner discussed how working in the garden environment provided a space which was a temporary distraction from routine prison life:

“It's just getting away from everything and it's like, sometimes I don't even see that fence...I don't even see it. To me, most of the time, until I really look on where it is, I forget where I $a m^{\prime \prime}$. (Female prisoner)

Improved relationships with staff 
Additional to improving relationships with fellow prisoners, GOOP has also helped develop relationships with prison staff, who were described as helpful and seen to treat the prisoners with respect. Prisoners had to demonstrate a degree of aptitude and common interest to participate in the programme and to be enrolled onto courses with vocational qualifications, which led to a reciprocal feeling of respect with staff:

"I get on with all these people and sort of just do what interests me and I'm encouraged to do that, so it's good...I think if you show them that you want to get on and you're not going to mess about...they're quite happy to teach you." (Male prisoner)

Echoing findings related to knowledge and skills, teaching and instruction from staff was praised:

"I think we work really, really well together...[He] is an amazing teacher...He comes in and he really listens." (Female prisoner)

\section{Reconfiguration of traditional prisoner status}

Where GOOP was becoming more embedded in general gardens activities, some participants emphasized how they had taken on additional responsibilities, resulting in mentoring and team leader roles:

[The instructor] comes in and he says he'd 'like to do this' and he'd 'like to do that'. And then he'll see what we think of his ideas and then we put our ideas together, and then it all comes together... sometimes he'll leave an instruction... But sometimes, because he's only here twice a week...say he wanted all this bit doing, this only takes half a day to do. So there's no more instructions, so I just take my own initiative..." (Female prisoner)

Whilst still ultimately under the direction of the college instructor and gardens manager, this increase in delegation and autonomy appeared to work effectively and made participants feel valued and empowered.

\section{Reconnection with local community}

Several prison sites allowed prisoners who met ROTL criteria to work outside prison on community sites and demonstration gardens at local horticultural shows:

"... with the encouragement of the garden staff... we were there doing the selling direct to the public. And after, you know, nearly a year inside, to interact with the public and actually sell stuff to them, that was quite good...l enjoyed that". (Male prisoner)

This illustrates how GOOP's outworking experiences allowed valuable interaction with the wider community beyond their usual peer cohort.

\section{Progression towards employment}

Prisoners were optimistically planning for legitimate horticulture-related employment postrelease directly related to experience gained on GOOP:

“...from my...exposure to it here, I'm confident in growing...stuff that I can take away with me and do when I get out, whether for my own use at home or whether to sell the stuff... When we're down the gardens...you say to each other, 'what are you going to do when you get out?' And a couple of lads have said, '...do you realise, you can actually sell that stuff?'" (Male prisoner) 
Examples were given of external organisations visiting the prison and offering work, initially through release on temporary licence, then as paid employment post-release on the basis of the participants' experience on GOOP:

"...this company have said, 'well we'll take you on then as well'. So I can actually be paid and earn the money before I'm released. And then on release, after prison I'll walk into that job as well, so I'm made up...it was an employer... Outreach...they came up to the prison and he took me on a visit... So he said 'there's a property maintenance job'". (Male prisoner)

This further supports the findings suggesting that GOOP has been effective in future-oriented knowledge and skills development.

\section{Personal and interpersonal wellbeing}

Whilst impacts related to skills development, qualifications and employment are of central importance, the data also reveal wider diverse effects linked to mental health. Some participants engaged with GOOP having no experience of gardening and, whilst still operating at a basic level, evidently enjoyed the work and valued their involvement. Looking postrelease, several felt that gardening would be a positive pastime which, although not linked to formal economic activity, was understood to be beneficial to their wider wellbeing:

"[Gardening will] probably be kept as a hobby. I'm thinking of getting an allotment...I really would like to have an allotment when I come out... I could make potatoes, you name it." (Male prisoner)

A recurring theme in the interviews was that participants had engaged in horticultural activities with a relative during their childhood, but had not continued this into adulthood. Participation in GOOP was therefore perceived to be an important way of reconnecting with family post-release:

"I love it here and I have learnt a lot more for when I go home working on my nanna's veg plot and flower gardens." (Female prisoner)

Engaging with GOOP in prison thus suggests a way to redevelop interpersonal relationships with elder relatives or to bond with younger family members who had yet to experience this kind of activity.

\section{Discussion}

The findings suggest strongly that participation in GOOP has been positive for prisoners' mental health and wellbeing. The quantitative data derived from the Green Gym $\odot$ and WEMWBS questionnaires revealed progress on the mental health indicators chosen by the funders (people feeling more confident to manage their everyday lives; people experiencing increased opportunities for social interaction; participants reporting new skills or knowledge gained). Complementing these, the narrative-based case studies elicited through BNIM interviews gave richer insights into the process and impacts of participants' involvement with GOOP. These illuminated not only the above indicators, but also multiple layers of added value linked to mental health and wellbeing - related to relationships, nature connectedness, preparation for employment and personal development. These wide-ranging impacts support findings from studies on the benefits of therapeutic and social horticulture programmes in 
other settings (Annerstedt and Wahrborg, 2011; Barton et al., 2016) and reflect the holistic vision of Health Promoting Prisons that underpins GOOP as a programme (Baybutt and Chemlal, 2016). Reflecting on this, the regularity with which those interviewed mentioned mental health is perhaps in itself unsurprising, given the high prevalence of problems amongst prisoners in the UK (The Bradley Report, 2009; Prison Reform Trust, 2015).

Work is an important determinant of mental health (Marmot et al., 2010) yet many prisoners have little or no employment experience and few marketable skills. Only one in four (27\%) have a job to go to when released (Prison Reform Trust, 2017). The importance of prisons providing skills development and meaningful work activities to help prepare prisoners for release cannot, therefore, be underestimated - but the Prison Reform Trust (2016b) reports that only $44 \%$ of prisons received a positive rating from inspectors during 2015-16 for purposeful work activity and that three quarters of prisons were judged as being inadequate or requiring improvement for learning and skills. Through offering accredited training and informal work experience, GOOP has begun to open up possibilities for participants contemplating life post-release. Importantly, GOOP aligns with a humanistic model of education, concerned with developing the whole person as well as vocational and employment skills. As Warr (2016) argues, there are important benefits to informal learning in terms of the development of greater wellbeing as well as self-confidence, self-esteem, empowerment and changed perspectives.

In addition, prison has a poor record for reducing reoffending, with nearly half of adults being reconvicted within one year of being released at huge personal, social and economic cost (National Audit Office, 2012). Evidence suggests that people are less likely to reoffend if they have a qualification (Prison Reform Trust, 2016b). 97 percent of offenders express a desire to stop offending, with $68 \%$ identifying 'having a job' as the most important influencing factor (Ministry of Justice, 2010). Most prisoners leave custody unprepared: without adequate opportunities to develop a work ethic, training to develop motivation and skills and systems to facilitate real employment, ex-prisoners face poor prospects on release, which contribute to high reoffending rates (Ministry of Justice, 2013b). Horticulture in custodial settings is recognised as a "vehicle for skills acquisition and promoting training and employment" (Grimshaw \& King, 2002: 4). Although prisoners highlighted the mental wellbeing benefits derived from spending time with like-minded peers doing something they enjoyed in a natureinfused environment that was safe, pleasant and restoring, the findings also revealed GOOP's positive role in providing challenging and rewarding work and in allowing participants to gain knowledge, skills and accredited training. Furthermore, the case studies made explicit links between participation in GOOP, securing accredited horticultural qualifications and potential employability post-release - a distinct area identified as relevant in effectively 'greening' prisons (Feldbaum et al., 2011). Whilst prisons are acknowledged as settings in which criminal enterprise can flourish (Neminski, 2014), the findings show how GOOP has facilitated enterprising participants to aspire to and plan for horticultural and related employment postrelease.

Conversely, there is a danger of instrumentalising the impact of horticultural and environmental work so that it becomes solely focused on accreditation and employment as a goal. Whilst certainly important, a 'one size fits all' approach fails to appreciate other impacts of GOOP. Participants' emotional development is especially significant in a prison environment. There is a cultural norm that prisoners should 'do their own time' and that any problems they are experiencing should be internalised (Scarce, 2002). While this study was 
not designed to consider the relative value of participation in GOOP compared to other prisonbased activities, the data suggests some distinctive benefits. Importantly, the process of caring for plants and flowers and creatively designing gardens can be understood as examples of biophilia, an 'urge to affiliate with other forms of life' (Wilson, 1984:85), which - for GOOP participants - seems to be leading to a more empathetic mindset towards other prisoners and staff. This was demonstrated in both the caring language used when describing nurturing the plants, but also in the changing relationships and an increased reciprocity between staff and prisoners working together to co-create new green spaces. This aligns with the prisons decency agenda - to increase attention to prisoners and respect their individual rights (Jewkes \& Bennett, 2011:61). Research has demonstrated the influence of supportive relationships and social networks on psychosocial and health outcomes for incarcerated people (Smoyer, 2015). The highly social and collaborative element of participating in GOOP arguably contributes to positive mental health - as increasing prisoners' sense of belonging through group interaction is an important part of wellbeing. Simplican et al. (2014) identify that such social inclusion promotes happiness, self-esteem, confidence, mental health and decisionmaking capacity and can better enable people to contribute to society.

One of the biggest threats to the progress made with GOOP participants was the perceived lack of continuity, moving from a smooth-running horticultural programme in prisons to communities with limited or no opportunities post-release. An initial aim of the evaluation was to follow GOOP participants 'through the gate', examining whether they were able to take skills learned on GOOP and put them to use in volunteering, employment or their everyday lives. Unfortunately, this aim was ultimately unfulfilled due to a number of factors: firstly, the probation service underwent a major restructure at the time of the study; and, secondly, legislation across prison and probation systems remains fragmented (Morris, 2016). This difficult transitional phase from prison to the community has been described as "deeply flawed" (Mitchell et al., 2002:2). There are consequently numerous challenges to such longitudinal research (e.g. issues of confidentiality preventing staff from communicating with prisoners who were engaged in GOOP post-release). For this to change, there is a need for a systems-level operational shift, enabling staff to track prisoners post-release; and for improved connections to be forged with community-based horticultural projects.

There were a number of challenges and limitations to the study, some specific to the prison context. The first of these was the difficulty that prison staff experienced in engaging participants to complete follow-on Green Gym (c) and WEMWBS questionnaires (12 weeks after joining GOOP and having collected baseline data). As a target population, prisoners demonstrate a paradoxical quality, in that they are both captive (they are detained in secure facilities) and transient (there is high mobility within the system, with prisoners frequently moving from one establishment to another). Limited staff resources meant it was not always possible to keep track of participants and they sometimes were transferred to another prison before having completed the 12 week questionnaires - rendering baseline data unusable. Furthermore, returned questionnaires were often incomplete with unanswered questions although, interestingly, there was more than twice the amount of data for questions regarding mental health and wellbeing than for questions regarding physical activity. When examining completed WEMWBS forms, validity concerns arose relating to response bias (Jackson, 2008:93). A number of participants filled in all responses on the follow-up WEMWBS questionnaire by ticking the same answer on the Likert scale for all 14 statements, often at the high (positive) end of the scale. It seems likely that some prisoners completed the form as quickly as possible and did not engage fully with the evaluation exercise; or that they felt compelled to show a dramatic improvement in their mental wellbeing score in order to reflect 
positively on the programme, perhaps for fear of the programme being cancelled and having restrictions placed on the amount of time outside of the cells that GOOP participants were enjoying. While there was no underlying incentive to report wellbeing improvements, and there is no evidence to suggest that prisoners did anticipate such sanctions, this combination of factors could potentially have resulted in the quantitative results being more positive than the reality of the participants' experience. For future studies, it could therefore be beneficial to incorporate professional (as well as self-perceived) assessment of mental health status at baseline and different stages in GOOP programme participation.

Resource constraints within the prisons and ethical issues concerning confidentiality made it impossible for staff to 'sift' questionnaires critically or to follow-up on individual responses to evaluation forms. All completed monitoring and evaluation forms were included in the data set for analysis, even when the research team suspected that the participant hadn't fully reflected on their experience when completing it. Furthermore, the remit of the funding body (to evaluate an initiative they had funded) meant that the research team did not have the resources to compare the experiences of prisoners not participating in the GOOP programme with those that were, to determine if there were any noticeable differences in self-perception of mental health and wellbeing.

Additionally, there are selection effects in the study: for the quantitative data, WEMWBS and Green Gym monitoring forms were only completed by participants who wished (or felt competent enough) to do so. For the BNIM interviews, participants were chosen through discussion with the gardens manager and staff concerning who would be both willing to give up their time to interview and who in particular liked to talk. Therefore, this was a small purposive sample of prisoners, although the study design ensured each category of prison was involved, and prisoners weren't selected on the basis of having 'positive' mental health stories, though it could be argued that prison staff selected prisoners they had more affinity with for these interviews.

\section{Conclusion}

The study's mixed method approach generated a large volume of data. Whilst there were some validity issues and some difficulties in gathering 'continuation' data, the quantitative data generated around mental health outcome areas was of sufficient quantity and quality to produce convergent findings about the impact of GOOP as a programme. Overall, this gave a promising, but not definitive picture of benefits to participation related to self-efficacy, an enhanced sense of community belonging and increased life skills.

Narrative-focused case-studies enabled the research team to go beyond the pre-defined outcome indicators to reveal several more layers of added value arising from participation in GOOP. In addition to highlighting a diversity of impacts, this generated a greater in-depth understanding of how participation affected individuals' mental health and wellbeing in a more intrinsic and holistic way.

The four prisons selected were chosen primarily to examine individuals' experiences in different category prisons ( $B, C, D$ and a women's prison). However, due to the unique context of each prison, this also enabled the research team to consider a variety of other factors (most noticeably, gender, but also size of prison and amount of green space available on site). This allowed the research team to understand the complexities involved in rolling out a programme across multiple sites, in turn offering beneficial learning for the future roll out of 
GOOP, informed by a whole system Health Promoting Prisons perspective, which focuses on rehabilitative culture in prisons ( $O^{\prime} B$ rien et al., 2014).

While holding onto the vision of a meaningful shift towards prisons as health promoting settings - prioritising rehabilitation, learning, reform and wellbeing (Woodall, 2012) - it is important to note that this and previous studies suggest that GOOP has impacted positively on prisoners even in harsh and forbidding environments that have a long way to go in embedding such perspectives and providing supportive and therapeutic conditions. As a result, GOOP has been 'mainstreamed' and is now operational in all public sector prisons in the North West of England and Wales. This suggests that the programme is sufficiently flexible to be applied in diverse contexts, including prisons of different category, population size, amount of green space available and age and gender of prisoner. Whilst it is inevitably challenging to do horticultural work in prisons which lack green space, gardens staff have used creative ways to ensure that this has become a reality. Building on this experience, it would also be valuable to explore whether additional benefits would accrue in contexts explicitly designed to be therapeutic: with this in mind, GOOP has already begun a pilot project in an Approved Premises (rebranded as Greener Outside), alongside expanding to prisons neighbouring the North West, with the intention of developing the programme further, both inside prison and outside in other related therapeutic settings.

Attempts to follow prisoners 'through the gate' to determine longitudinal benefits of the programme highlighted inherent difficulties in working across prison and community settings. The study thus highlighted the need for a systems-level shift in how this challenging transition is managed, in order to facilitate positive wellbeing outcomes from GOOP being transferred into communities post-release. Correspondingly, there is a need for a longitudinal study examining the experiences of participants leaving prison to determine any long-standing benefits of participation in GOOP or other congruent horticultural programmes.

\section{Acknowledgements}

This research was funded by Big Lottery Fund. The funding body specified that data should be gathered on specific outcome indicators, but also allowed the research team to search for additional outcomes from the programme. 


\section{References}

Allen, G. and Watson, C. (2017) Prison Population Statistics. Briefing Paper Number $\mathrm{SN} / \mathrm{SG} / 04334,20^{\text {th }}$ April 2017. House of Commons Library. researchbriefings.files.parliament.uk/documents/SN04334/SN04334.pdf <accessed $6^{\text {th }}$ October 2017>

Almalki, S. (2016) Integrating Quantitative and Qualitative Data in Mixed Methods Research - Challenges and Benefits. Journal of Education and Learning, 5(3): 288-296.

Annerstedt, M and Wahrborg, P. (2011) Nature-assisted therapy: systematic review of controlled and observational studies. Scandinavian Journal of Public Health. 2011 Jun; 39(4): 371-88.

Barton, J., Bragg, R., Wood, C. and Pretty, J. (Eds.) (2016) Green Exercise: Linking Nature, Health and Well-being. Routledge.

Baybutt, M., Acin, E., Hayton, P. and Dooris, M. (2014) Promoting health in prisons: a settings approach. In: Enggist S, Møller L, Galea G, Udesen C. (Eds.) Prisons and health. Copenhagen: WHO; 2014: 180-184.

Baybutt, M. and Chemlal, K. (2016) Health Promoting Prisons: Theory to Practice. Global Health Promotion 23 (Suppl. 1): 67-74.

Baybutt, M., Farrier, A. and Dooris, M. (2012) Target: Wellbeing Pan-Regional Prisons Programme - Health, Inclusion and Citizenship. Final Report. Preston: UCLan - Healthy \& Sustainable Settings Unit.

The Bradley Report (2009) Lord Bradley's review of people with mental health problems or learning disabilities in the criminal justice system (April 2009). London: DoH.

Department of Health (2002) Health Promoting Prisons: A Shared Approach. HM Government: DoH.

Department of Health (2004) Choosing Health: Making Healthier Choices Easier (November 2004). HM Government: DoH.

Farrier, A., Dooris, M. and Froggett, L. (2017) Five Ways to Wellbeing: holistic narratives of public health programme participants. Global Health Promotion. ISSN 1757-9759.

Feldbaum, M., Greene, F., Kirchenbaum, S., Mukamal, D., Welsh, M. and Pinderhughes,

R. (2011) The Greening of Corrections: Creating a Sustainable System. United States Department of Justice National Institute of Corrections.

Giles, S.,Phillips, S., Timpson, C., Carlin, H., Perkins, C., Dooris, M. and Farrier, A. (2010) Target: Wellbeing Evaluation - Annual Report February 2010 (Reporting period AprilSeptember 09). Liverpool: LMU - NWPHO.

Grimshaw, R. \& King, J. (2002) Horticulture in secure settings: A study exploring social and therapeutic horticultural activities in prisons and secure psychiatric facilities in the United Kingdom. Thrive Briefing Sheet No.5.

Groundwork (2015) Targeting Wellbeing: How We Helped 205,237 People Live Healthier and Happier Lives. Portfolio Impact Report (August 2015). Big Lottery; Groundwork. 
The Hepatitis C Trust (2013) Addressing Hepatitis C in prisons and other places of detention: Recommendations to NHS England (May 2013). London.

http://www.hcvaction.org.uk/sites/default/files/resources/HCV\%20in\%20Prisons.pdf $<$ accessed $6^{\text {th }}$ October 2017>

The Howard League for Penal Reform and Centre for Mental Health (2016) Preventing Prison Suicide. Centre for Mental Health. http://howardleague.org/wp-

content/uploads/2016/11/Preventing-prison-suicide-report.pdf $<$ accessed 31st August 2017>

HM Government (2005) Reducing Re-Offending Through Skills and Employment. (December 2005). Norwich: The Stationary Office.

Jackson, S. (2008) Research Methods: A Modular Approach. USA: Thomson Wadsworth.

Jewkes, Y. \& Bennett, J. (2011) Dictionary of Prisons and Punishment. London: Routledge.

Marmot, M., Allen, J., Goldblatt, P. et al. (2010) Fair society, healthy lives: strategic review of health inequalities in England post 2010. London: Marmot Review Team.

Ministry of Justice (2010) Breaking the Cycle: Effective Punishment, Rehabilitation and Sentencing of Offenders. The Stationary Office: London.

Ministry of Justice (2013a) Story of the Prison Population 1993-2012 England and Wales (January 2013).

https://www.gov.uk/government/uploads/system/uploads/attachment data/file/218185/st ory-prison-population.pdf <accessed 6th October 2017>

Ministry of Justice (2013b) Transforming Rehabilitation: a summary of evidence on reducing reoffending. Ministry of Justice Analytical Series 2013.

https://www.gov.uk/government/uploads/system/uploads/attachment data/file/243718/e vidence-reduce-reoffending.pdf <accessed 6th October 2017>

Ministry of Justice (2014) Statistics on Women and the Criminal Justice System. https://www.gov.uk/government/uploads/system/uploads/attachment data/file/380301/in fographic-women-and-the-criminal-justice-system.pdf $<$ accessed 6th October 2017>

Mitchell, C., Parent, D. G. and Barnett, B. (2002) Transition from prison to community initiative. Washington: National Institute of Corrections.

https://s3.amazonaws.com/static.nicic.gov/Library/017520.pdf $<$ accessed 6th October 2017>

Morris, M. (2016) A whole-system approach to offender management - Report (December 2016). Institute for Public Policy Research. London.

https://www.ippr.org/files/publications/pdf/a-whole-system-approach-Dec16.pdf $<$ accessed 6th October 2017>

National Audit Office (2012) Comparing International Criminal Justice Systems, London: National Audit Office.

Neminski, M. (2014) The Professionalization of Crime: How Prisons Create More Criminals. The Core Journal, 23 (Spring 2014) pp. 81-92.

http://www.bu.edu/av/core/journal/journal14.pdf <accessed 6th October 2017>

NHS Health Scotland (2006) The Warwick-Edinburgh Mental Well-being Scale (WEMWBS). 
http://www.healthscotland.com/uploads/documents/3047-Measuring\%20mental\%20wellbeing\%20\%20Affectometer\%202\%20-\%20WEMWBS\%20briefing.pdf $<$ accessed $30^{\text {th }}$ August 2017>

NOMS (2015) Prison Service Instrument 13/2015: Release On Temporary Licence (PSI 13). https://www.justice.gov.uk/offenders/psis <accessed 6thth October 2017>

O'Brien, R., Marshall, J. and Karthaus, R. (2014) Building a rehabilitation culture. RSA Transitions.

https://www.thersa.org/globalassets/pdfs/reports/rsa building a rehabilitation culture 1 106 14.pdf <accessed 20th October 2017>

Prisons and Probation Ombudsman Independent Investigations (2016) Annual Report 201516 (September 2016). London: OGL.

Prison Reform Trust (2015) Bromley Briefings Prison Factfile Autumn 2015 London: Prison Reform Trust. http://www.thebromleytrust.org.uk/files/bromleybriefingsautumn2015.pdf $<$ accessed $24^{\text {th }}$ November 2017>

Prison Reform Trust (2016a) Mental Health Care In Prisons.

http://www.prisonreformtrust.org.uk/ProjectsResearch/Mentalhealth <accessed 31/08/2017>

Prison Reform Trust (2016b) Bromley Briefings Prison Factfile Autumn 2016 London: Prison Reform Trust.

http://www.prisonreformtrust.org.uk/Portals/0/Documents/Bromley\%20Briefings/Autumn \%202016\%20Factfile.pdf $<$ accessed $13^{\text {th }}$ September 2017>

Prison Reform Trust (2017) Prison: the facts. Bromley Briefings Summer 2017.

http://www.prisonreformtrust.org.uk/Portals/0/Documents/Bromley\%20Briefings/Summer \%202017\%20factfile.pdf <accessed $20^{\text {th }}$ Oct $2017>$

Public Health England (2016) Health \& annual review 2015/16. Public Health England, World Health Organisation.

https://www.gov.uk/government/uploads/system/uploads/attachment data/file/562181/H ealth and justice annual review 2015-2016.pdf <accessed 6th October 2017>

Scarce, J.R. (2002) 'Doing time as an art of survival.' Symbolic Interaction, 25 (1): 303-321.

Simplican, S.C., Leader, G., Kosciulek, J and Leahy, M (2014) Defining social inclusion of people with intellectual and developmental disabilities: An ecological model of social networks and community participation. Research in Developmental Disabilities 38: 18- 29.

Smoyer, A.B. (2015) Feeding Relationships: Foodways and Social Networks in a Women's Prison. Journal of Women and Social Work Vol. 30 (1): 26-39.

Social Exclusion Unit (2002) Reducing Re-offending by Ex-prisoners. London: Office of the Deputy Prime Minister.

Springett, J. (2001) Appropriate approaches to the evaluation of health promotion, Critical Public Health, 11: 139-151.

Warr , J. (2016) Transformative dialogues: (Re)privileging the informal in prison education. Prison Service Journal, May 2016. 
https://www.crimeandjustice.org.uk/sites/crimeandjustice.org.uk/files/PSJ\%20225\%20May \%202016.pdf, accessed $6^{\text {th }}$ October 2017>

Warwick-Booth, L., Cross, R., and Lowcock, D. (2012). Contemporary health studies: an introduction. Cambridge: Polity Press.

Wengraf, T. (2001) Qualitative Research Interviewing: Biographic Narrative and SemiStructured Methods. UK: SAGE Publications.

Wilson, E.O. (1984) Biophilia: The Human Bond with other Species. Cambridge: Harvard University Press.

Woodall, J. (2012) Health promoting prisons: an overview and critique of the concept. Prison Service Journal, 202:6-11.

Woodall, J., Dixey, R and South, J. (2014a) Control and choice in English prisons: developing health-promotion prisons. Health Promotion International, 29(3):474-82.

Woodall, J., de Viggiani, N., Dixey, R. and South, J. (2014b) Moving prison health promotion along: toward an integrative framework for action to develop health promotion and tackle the social determinants of health. Criminal Justice Studies, 27(1):114-32. 